\title{
sciendo
}

CIVIL AND ENVIRONMENTAL ENGINEERING REPORTS

E-ISSN 2450-8594

CEER 2020; 30 (2): 0065-0079

DOI: $10.2478 /$ ceer-2020-0020

Original Research Article

\section{DIGITAL ANALYSIS OF GEO-REFERENCED CONCRETE SCANNING ELECTRON MICROSCOPE (SEM) IMAGES}

\author{
Mohd Sanusi S. AHAMAD ${ }^{1}$, Elly Nur Myaisara MAIZUL \\ School of Civil Engineering, Engineering Campus, Universiti Sains Malaysia
}

\begin{abstract}
The microstructural evaluation of complex cementitious materials has been made possible by the microscopic imaging tools such as Scanning Electron Microscope (SEM) and X-Ray Microanalysis. Particularly, the application of concrete SEM imaging and digital image analysis have become common in the analysis and mapping of concrete technology. In this study, six samples of two-dimensional (2D) SEM images were spatially resampled to produce Geo-referenced SEM sample images. Subsequently, they were analyzed and the intensity histogram plot was produced to facilitate visual interpretation. The consecutive digital image analysis performed was the enhancement and noise removal process using two filtering methods i.e. median and adaptive box filter. The filtered resampled images, then undergone the unsupervised K-Means classification process to collectively separate each individual pixel corresponds to the spectral data. By spatial segmentation of K-Means algorithms, the cluster groups generated were carefully reviewed before proceeding to the final analysis. From the resulting data, the mapping of the spatial distribution of k-cluster and the quantification of micro-cracks (voids) were performed. The results of the SEM images $\left(1^{\text {st }}-4^{\text {th }}\right.$ sample) showed a higher percentage of k-cluster data indicating a good correlation with the major elemental composition of EDX analysis, namely Oxide $(\mathrm{O})$, Silicon $(\mathrm{Si})$ and Carbon $(\mathrm{C})$. Meanwhile, the subjective visual assessment of the image $\left(5^{\text {th }}\right.$ and $6^{\text {th }}$ sample) has confirmed the micro-crack developments on the concrete SEM images upon which the crack density was $3.02 \%$ and $1.30 \%$, respectively.
\end{abstract}

Keywords: scanning electron microscope, geo-referenced image, digital image analysis, image mapping

${ }^{1}$ Corresponding author: Mohd Sanusi S. Ahamad, School of Civil Engineering, Engineering Campus, Universiti Sains Malaysia, e-mail: cesanusi@usm.my, +605-5996277 


\section{INTRODUCTION}

Concrete is undeniably the prime construction material of any man-made structural applications. Traditionally, the assessment of concrete performance is done via its physical mechanical behaviour. However, the complexities of concrete microstructure have led to variously advanced study with respect to their influence in the engineering properties of concrete. From a microscopic point of view, concrete is defined as a three-phase composite mass comprising a mortar matrix, a aggregate and an interfacial transition zone (ITZ) between them [1]. The concrete microstructure can be analyzed by numerous investigation techniques such as Mercury Intrusion Porosimeter (MIP), Light Optical Microscopy (OM) together with digital image analysis, Scanning Electron Microscopy (SEM) and X-ray Micro-computed Tomography (MCT) with image processing [2]. However, the modern SEM imaging and X-ray microanalysis methods can contribute to a greater finding in the complex concrete microstructure imaging [3]. In addition, the application of digital image processing (DIP) to different microscopic images provided quantitative data that would be useful for any objective comparison. Over the past years, the utilization of SEM in concrete studies is becoming more well-known. Due to the vast development in concrete technology, the SEM imaging study on the microstructure of concrete has extensively accomplished by countless researchers [4-8]. The research work focused specifically on the evaluation of the concrete ITZ in the bonding strength [9-11]. Research has shown that microcracking of concrete exposed to high temperatures can be further investigated using a digital image processing tool [12-14]. In this regard, the assessment of high-performance concrete (HPC) is best performed under SEM, which will include more advanced image analysis [15-17] Consequently, the findings of past research have shown that the SEM analysis of concrete microcharacteristics can provide a deeper understanding of concrete behaviour and the diagnosis of concrete complexities.

The SEM image is a 2D intensity map in digital domain where each image pixel on the display corresponds to a point on the sample, which is proportional to the signal intensity captured by the detector at each specific point in 8 bits (256 grey levels). Typically, these characteristics are identical to the Raster Geographic Information System (GIS) images. If the SEM can be geo-referenced or assigned coordinates (in sub-millimetres), then standard GIS quantitative mapping will be possible. In addition, standard image segmentation, enhancement, and classification tools in the GIS image processing technology have been frequently used in the context of quantitative analysis of cementitious materials, on images acquired with Scanning Electron Microscope [18-22]. 


\section{DIGITAL IMAGE PROCESSING}

In the assessment of concrete microstructure properties, this work applies GISbased digital image processing techniques to SEM cement specimens. Digital analysis and mapping of concrete SEM images were performed to identify various task such as the interfacial transition zone (ITZ) of normal concrete (NC) and green ultra-high-performance fibre reinforced cementitious composite (UHPFRC), recognizing and measuring crack density from high-temperature exposure, and mapping the elemental compositions present in the image.

A digital image is composed of a finite number of elements named pixels, which has its own location and value. Images are stored in various image file formats such as RAW, BMP, GIF, JPEG and TIFF. Primarily, these are designed to preserve the high image quality with low storage consumption, quick transference, simple transformation to other formats and straightforward editing/processing [23]. With the advancement of modern computerization and image sensor technologies, digital image processing has become more vital in the sense of substituting the conventional film-based photomicrograph in microscope imaging [24]. Two major application areas of digital image processing are the enhancement of pictorial information for human interpretation and organizing of scene data for autonomous machine perception [25]. The computational approach in image analysis includes various processing techniques, namely enhancement, segmentation, detection of the region of interest, pre-filtering method, thresholding technique and morphological operations [26].

\subsection{Intensity Histogram}

The Histogram plot of a digital image is a distribution of its distinct intensity level within the range. It is essentially a graph showing the number of pixels between 0 (dark) and 256 (light) in an image at each varying intensity value found. In the context of image processing, the distribution of level intensity will provide the user information on the global appearance of the image and its properties. Moreover, the intensity histogram is useful when performing further image processing such as image enhancement, image compression, and image segmentation It assists in detecting image acquisition problems such as image exposedness (over or under exposure), brightness, contrast or dynamic range [27].

\subsection{Image Enhancement}

Image enhancement is an action of rendering digital images for better human visual interpretation and/or the suitability for computational analysis on the processed images. In signal processing, noise is unwanted information present in 
a digital image formed during the process of storage, transmission, processing, or conversion [28]. Primary emission, secondary emission, scintillator, photocathode and photomultiplier are the sources from which noise pulses are generated [29]. The reduction of background noise in SEM images is important in many cases because it showed significant benefits in image analysis [30, 31]. Filtering noise is the most efficient way to preserve and reduce the complexities of digital images without significantly altering the quality of SEM images.

\subsection{Image Classification}

Image classification will categorize each individual pixel correspond to the spectral data by assigning a unique value and/or its own grey level or colour. It is also known as image segmentation in computer vision, a process of segmenting a digital image into sets of pixels known as super-pixels [32]. In general, image segmentation and classification process are interrelated, a classifier implicitly segments an image and on the other hand, a segmentation implies a classification.

$\mathrm{K}$-means clustering is an unsupervised classification method that divides a dataset comprising of $\mathrm{n}$ points embedded in $\mathrm{m}$-dimensional space into $\mathrm{K}$ clusters such that the data points within a cluster are more 'similar' among the other data points in another cluster. The term 'similar' implies as it means closer by some similarity measures such as the pixels with the same label share certain characteristics like objects and boundaries (lines, curves, etc.). Therefore, the results of the K-means clustering algorithm are the centroids of the $\mathrm{K}$ clusters, which can be used to label new data and the labels for the training data (each data point is assigned to a single cluster).

\subsection{Microstructure Properties Evaluation}

The method of microscope imaging and image analysis is particularly useful in qualitatively or semi-quantitatively mapping the composition and distribution of particles in concrete microstructure-property relations using SEM image data on the selected surface area of the specimen. A work by [33] examined the original image of SEM backscattered electron by quantitatively analysing the ground blast furnace in cement-slag paste (GBFS). The method was found effective in analysing the content of GBFS in hardened cement pastes. Concurrently, [34] investigated the image processing technique in quantifying cracks area in electrodeposits. The study uses the second derivative of the histogram obtained with Laplacian of Gaussian (LoG) together with Prewitt vertical edge detector to generally access the spatial cracked area by comparing the data with the subjective visual assessment. Another related study [35] introduces new interactive approach for segmentation and classification of cementitious materials using Scanning Electron Microscope images. It is based on the denoising of the data with the Block Matching 3D (BM3D) algorithm, Binary 
Partition Tree (BPT) segmentation and Support Vector Machines (SVM) classification. The BPT provides a hierarchical representation of the spatial regions of the data and, after sufficient pruning, generates a segmentation map that can be enhanced by the user.

Table 1. Review summary of the research works

\begin{tabular}{|c|c|c|c|c|c|}
\hline \multirow{2}{*}{ Ref. } & \multirow{2}{*}{$\begin{array}{c}\text { Digital Image } \\
\text { Types }\end{array}$} & \multicolumn{4}{|c|}{ Digital Image Processing Techniques } \\
\hline & & HA & IE & IC & IS \\
\hline [33] & SEM-BSE Images & l & Filter & $\mathrm{X}$ & $\mathrm{x}$ \\
\hline [34] & SEM Images & / & $\begin{array}{c}\text { Laplacian of } \\
\text { Gaussian } \\
\text { (LoG) }\end{array}$ & $\mathrm{x}$ & $\begin{array}{c}\text { Prewitt } \\
\text { Vertical Edge } \\
\text { Detection }\end{array}$ \\
\hline$[35]$ & SEM-BSE Images & / & $\begin{array}{c}\text { Block } \\
\text { Matching 3D } \\
\text { (BM3D) } \\
\text { Algorithm }\end{array}$ & $\begin{array}{c}\text { Support Vector } \\
\text { Machines }+ \\
\text { Markov } \\
\text { Random Field } \\
\text { (MRV) } \\
\text { Regulation }\end{array}$ & $\begin{array}{c}\text { Binary } \\
\text { Partition Tree } \\
\text { (BPT) }\end{array}$ \\
\hline [36] & $\begin{array}{l}\text { Micro-Digital } \\
\text { Images }\end{array}$ & $\mathrm{x}$ & $\mathrm{x}$ & $\mathrm{x}$ & $\begin{array}{c}\text { Global } \\
\text { Threshold }\end{array}$ \\
\hline$[37]$ & $\begin{array}{l}\text { SEM and Optical } \\
\text { Micro-(OM) } \\
\text { Images }\end{array}$ & $\mathrm{x}$ & $\begin{array}{c}\text { Gaussian } \\
\text { Filtering, } \\
\text { Sobel Filters }\end{array}$ & $\begin{array}{c}\text { Watershed } \\
\text { Algorithm, } \\
\text { Globular Alpha } \\
\text { Segmentation }\end{array}$ & / \\
\hline [38] & $\begin{array}{l}\text { BSE Image + X- } \\
\text { Ray Micro- } \\
\text { Elemental Maps }\end{array}$ & $\mathrm{x}$ & $\begin{array}{l}\text { Fourier } \\
\text { Transform }\end{array}$ & $\begin{array}{l}\text { SVM-MRF } \\
\text { Algorithm }\end{array}$ & $\mathrm{X}$ \\
\hline [39] & SEM Images & $\mathrm{x}$ & Median Filter & $\mathrm{x}$ & $\begin{array}{l}\text { K-Means, } \\
\text { Watershed }\end{array}$ \\
\hline
\end{tabular}

Note: HA - Histogram Analysis; IE- Image Enhancement; IC - Image Classification; IS - Image Segmentation

Meanwhile, [36] experimented the image processing method such as global thresholding and noise filtering technique onto the actual digital images of the grinding wheel surface as the study aimed to have a quantitative analysis of wheel loading. A new method was proposed by [37] in image processing for automating the measurement of microstructural SEM images where it utilized the filtering technique, watershed transformation, region merging, phase separation and measurement process. In addition, [38] studied the multispectral image datasets (backscattered electron (BSE) image combined with X-ray microanalysis elemental maps) of cementitious paste. The study has explored the application of merged image processing algorithms such as Support Vector Machine (SVM) and Markov Random Field (MRF) algorithms in quantifying 
the supplementary cementitious materials particularly fly ash, slag and natural pozzolans. Similarly [39], established the pixel length criterion for filtering noise and other highlighted features of concrete microstructure at three different magnification factors. The study concluded that a proper selection of image processing operations was needed by the automated quantitative microstructural analysis of concrete micro cracks and voids systems. From the study, it can be observed that using modern imaging technology such as Scanning Electron Microscopy (SEM), supported by image processing and analysis, most researchers can have better judgment and important investigation in defining the properties of the concrete microstructure. Table 1 provides the review summary of the research works related to microstructure properties evaluation using the image processing tool.

\section{MATERIALS}

\subsection{SEM Samples}

Two different type of concrete SEM specimens were examined, namely, sandblasted (POSB) concrete and grinded (POGR) concrete images. These image samples were obtained from a specific SEM research work that studies the effects of bonding between NC and UHPFRC. Six concrete Scanning Electron Microscope (SEM) images were selected for the image processing study. The primary information of the SEM image specimens is described in Table 2.

Table 2. Primary information of raw concrete SEM samples

\begin{tabular}{|c|c|c|c|}
\hline SEM Images & Working Distance (WD) & Magnification Scale & Scale \\
\hline Sample 1 & $8.4 \mathrm{~mm}$ & $200 \times$ & $500 \mu \mathrm{m}$ \\
\hline Sample 2 & $10.3 \mathrm{~mm}$ & $200 \times$ & $500 \mu \mathrm{m}$ \\
\hline Sample 3 & $10.5 \mathrm{~mm}$ & $100 \times$ & $1 \mathrm{~mm}$ \\
\hline Sample 4 & $10.5 \mathrm{~mm}$ & $100 \times$ & $1 \mathrm{~mm}$ \\
\hline Sample 5 & $10.2 \mathrm{~mm}$ & $200 \times$ & $500 \mu \mathrm{m}$ \\
\hline Sample 6 & $10.3 \mathrm{~mm}$ & $200 \times$ & $500 \mu \mathrm{m}$ \\
\hline
\end{tabular}

\section{METHODOLOGY}

\subsection{Image Acquisition}

The two-dimensional unprocessed SEM images were monochrome images obtained from a study that investigates the cracking phenomenon on the concrete specimens after fire exposure. The samples have undergone two different types of surface treatment namely, sandblasting and grinding, later exposed to elevated 
temperature. The GIS image processing software converts them into simple TIFF files that supports multiple-band images. Their metadata are specified as TIF file with dimension (1024 x 943) pixels, and 84 DPI uncompressed.

\subsection{Image Resampling}

Resampling process transformed the sampled images from the non-coordinate system to a scalable coordinate. It applies a mathematical approach of creating a new version of the image with a scaled dimension on the width/height of the pixels. The process allows an image to be up-sampled or down-sampled.

\subsection{Generating Histogram}

The frequency distribution graph, i.e. histogram can describe the number of pixels in an image at every different intensity value. The histogram provides basic statistical data such as mean and standard deviation of the histogram values to gain more insight on its significance with respect to the image processing.

\subsection{Noise Filtering}

Filtration improves the quality of the digital image and eliminates the presence of random noise due to interruption during image storage, transmission and processing. The nonlinear digital filtering technique i.e. adaptive box filter and median filter are used for this task. It removes the random noise and the noisy data due to pixel brightness that has an additive or multiplicative noise factor.

\subsection{K-Means Clustering}

This is an unsupervised classification approach that classifies input data points into multiple clusters based on their inherent distance from each other. The points are clustered around the centroids. A different value of the initial centroid will result in another cluster. The process will partition n-dimensional imagery into K-exclusive clusters and determine the K-centroids.

\subsection{Mapping Concrete SEM Images}

Due to the intense distinction in topographical contrast, the Interfacial Transition Zone (ITZ) of two cementitious materials was distinguished easily. The Kmeans clustering technique applied has collectively divided the pixel intensities into 15 possible k-clusters. Prior to the former spectrum data, both inspection areas were cropped. Figure 1 provided an example of the cropped process in concrete SEM sample 1. The resulting data can be quantified to acquire the spatial distribution of each cluster. For this purpose, four concrete SEM images were selected. The SEM Sample 1 and Sample 2 images represent matured 28 days of concrete specimens that have undergone a different surface treatment. While, the SEM Sample 3 and 4 images were the resulting concrete images that 
have been exposed to $200^{\circ} \mathrm{C}$ of temperature and been treated to different surface preparation of grinding and sandblasting, respectively.

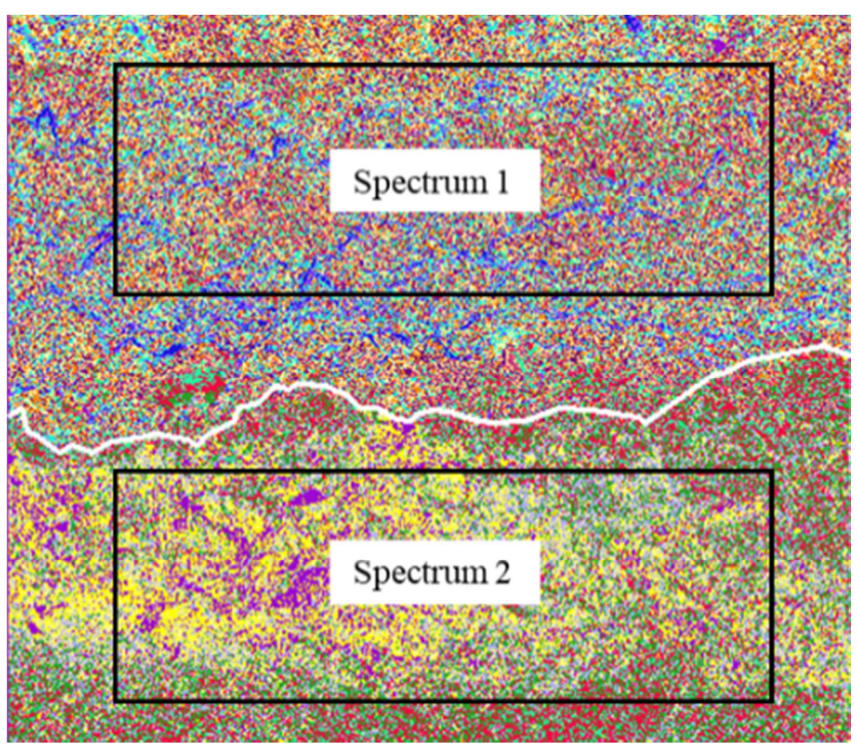

Fig. 1. Cropped areas in Concrete SEM Sample 1

\subsection{Identification and Quantification of Micro-cracks and Voids}

From the unsupervised K-means classification of filtered images, the resulting cluster groups defined the group of similar meaningful regions based on the intensity of the pixels. The cluster group representing the micro-cracks and voids feature was determined. Consequently, it was reclassed using integer ID values of raster files. The insignificant cluster groups were reclassed to zero as this study interests in identifying the segmented micro-cracks and voids. The quantification process of crack density was computed using Equation (4.1) [40]:

$$
\text { Crack Density }=\frac{\text { Total Crack Length }(\mu \mathrm{m})}{\text { Image Field Area }\left(\mu \mathrm{m}^{2}\right)}
$$

Unlike other specific image processing software, GIS-software capability has some limitation where it cannot automatically recognize and quantify the microcracks and voids length. Thus, the crack density formula was adjusted as in Equation (4.2):

$$
\text { Crack Density }(\%)=\frac{\text { Total Crack Area }\left(\mu m^{2}\right)}{\text { Image Field Area }\left(\mu m^{2}\right)}
$$


Two SEM images were analyzed, namely Sample 5 and Sample 6. Since both concrete samples have undergone fire exposure at $500^{\circ} \mathrm{C}$, therefore the microcracks and voids can be seen by the naked eye. The scale conversion of $1 \mathrm{~mm}$ of the actual image is equivalent to 1 meter in the image. Therefore, analytically each image produced a total area of $7.68 \mathrm{~m}^{2}$.

\section{RESULTS AND DISCUSSIONS}

\subsection{Choice of Noise Filter}

Table 3 shows the differences in minimum/maximum values obtained from the resampled images from the succeeding median and adaptive box filtering for noise removal.

Table 3. Median filter and adaptive box filter

\begin{tabular}{|c|c|c|c|c|c|c|}
\hline \multirow{2}{*}{ SEM Images } & \multicolumn{2}{|c|}{ Resampled Image } & \multicolumn{2}{c|}{$\begin{array}{c}\text { Median Filtered } \\
\text { Image }\end{array}$} & \multicolumn{2}{c|}{$\begin{array}{c}\text { Adaptive Box } \\
\text { Filtered Image }\end{array}$} \\
\cline { 2 - 7 } & Min & Max & Min & Max & Min & Max \\
\hline Sample 1 & 0 & 243 & 18.50 & 212.00 & 0.00 & 233.00 \\
\hline Sample 2 & 0 & 248 & 20.00 & 222.00 & 0.00 & 248.00 \\
\hline Sample 3 & 0 & 216 & 7.00 & 203.00 & 0.00 & 216.00 \\
\hline Sample 4 & 0 & 255 & 8.00 & 255.00 & 0.00 & 255.00 \\
\hline Sample 5 & 0 & 231 & 15.50 & 213.00 & 0.00 & 231.00 \\
\hline Sample 6 & 0 & 255 & 6.00 & 254.00 & 0.00 & 255.00 \\
\hline
\end{tabular}

The median filtering has drastically amended the minimum/maximum values of the SEM images. For example, Sample 1, min/max (0/243) changes to (18.50/ 212.00). The adaptive box filtering, however, preserved the minimum zero value but slightly adjusted the maximum value to 233.00. Adaptive box filtering has been verified reliable in improving the SEM image quality and was adopted in the subsequent image processing stage [41].

\subsection{Spatial Distribution of Concrete SEM Images}

The spatial distribution of each cluster is largely affected by the k-centroid selection. The obvious graphical contrast for each inspection zone has grouped the cluster with respect to the differences. For example, for concrete Sample 1 (Table 4), the intensities spreading for both spectrums are generally inconsistent. Spectrum 1 has a better and concerted dispersion of cluster group while spectrum 2 has a major non-uniform intensities distribution. For cluster groups that have less than $1 \%$ of diffusion, the respective cluster is practically negligible. In addition, six cluster groups in spectrum 2 have zero percentage as the concentrated k-centroid fell on the top part of the image sample i.e. spectrum 
1. The highest percentage of k-cluster probably refers to the major elements presented in the concrete SEM image which are Oxide (O), Silicon $(\mathrm{Si})$ and Carbon (C). Based on the individual percentage of cluster, it can be deduced that some of the k-clusters were having almost homogenous distribution as stated by [42] i.e. evenly clustered data is due to the assumption in K-means that confirm the Expectation Maximization (EM) algorithm that predicts all clusters are to be equally sized and have similar variances. As for the lower percentage of kcluster, the supposition of a spatial composition is associated with chemical elements such as $\mathrm{Fe}, \mathrm{Mg}$, $\mathrm{Na}, \mathrm{K}$, and $\mathrm{Al}$. The similar pattern of k-cluster scattering was also detected in other samples

Table 4. Analysis of K-cluster distribution

\begin{tabular}{|c|c|c|c|c|}
\hline \multicolumn{7}{|c|}{ SEM Sample 1 } \\
\hline Sumber and Percentage of Pixels) \\
\hline 1 & 1 & $\%$ & 2 & $\%$ \\
\hline 2 & 11344 & 4.81 & 25994 & 11.12 \\
\hline 3 & 33891 & 14.38 & 22 & 0.01 \\
\hline 4 & 5030 & 2.13 & 42202 & 18.06 \\
\hline 5 & 33622 & 14.27 & 113 & 0.05 \\
\hline 6 & 444 & 0.19 & 25652 & 10.97 \\
\hline 7 & 15648 & 6.64 & 8155 & 3.49 \\
\hline 8 & 24822 & 10.53 & 964 & 0.41 \\
\hline 9 & 18102 & 7.68 & 0 & 0.00 \\
\hline 10 & 31265 & 13.27 & 344 & 0.15 \\
\hline 11 & 31894 & 13.53 & 1 & 0.00 \\
\hline 12 & 612 & 0.26 & 40936 & 17.51 \\
\hline 13 & 5220 & 2.21 & 0 & 0.00 \\
\hline 14 & 2151 & 0.91 & 47093 & 20.15 \\
\hline 15 & 924 & 0.39 & 39417 & 16.86 \\
\hline Total & 20714 & 8.79 & 2839 & 1.21 \\
\hline & 235683 & 100 & 233732 & 100 \\
\hline
\end{tabular}

\subsection{Micro-cracks and Voids}

In quantifying the presence of micro-cracks in the concrete SEM images, the crack density was calculated using Equation (2). where the total image field area is $7.68 \mathrm{~mm}^{2}(3.0 \mathrm{~mm} \times 2.56 \mathrm{~mm})$. Figure 2 shows the derivation of the crack density of sample 5 having $3.02 \%$ of existing micro-cracks and voids. Meanwhile, sample 6 in Figure 3 has a lesser crack density of $1.30 \%$. Table 5 presents the summarization of crack density for the concrete SEM images. The crack density occupies rather a micro scale in the SEM images. In actual calculation, $1 \mathrm{~mm}$ (1m image Scale) is represented by $500 \mu \mathrm{m}$ (Actual SEM 
Magnification). The true measurement of the micro-cracks and voids of the SEM images are up to $5000 \times$, according to the magnification scale during the SEM image acquisition process.
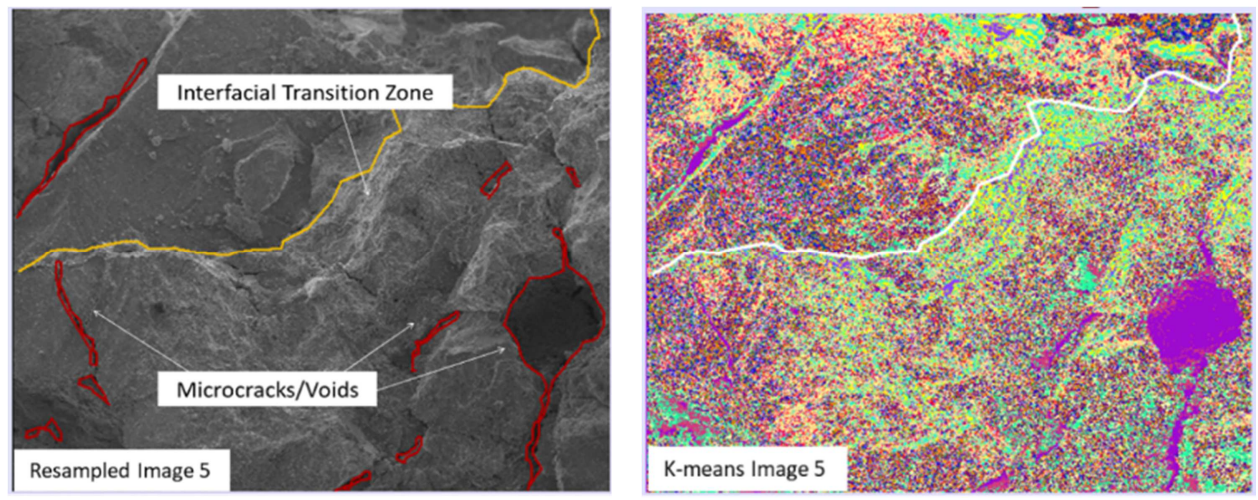

Fig. 2. Possible deterioration evidences in concrete SEM sample 5
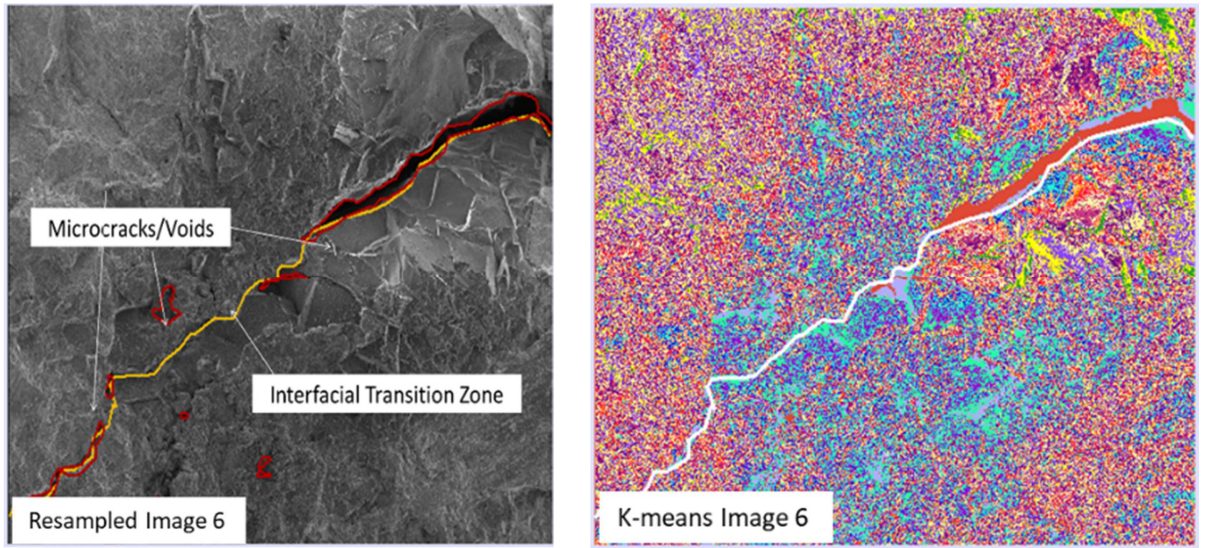

Fig. 3. Possible deterioration evidences in concrete SEM sample 6

Table 5. Micro-crack density for concrete SEM images

\begin{tabular}{|c|c|c|c|c|}
\hline $\begin{array}{c}\text { SEM } \\
\text { Specimen }\end{array}$ & $\begin{array}{c}\text { Actual } \\
\text { Scale }\end{array}$ & $\begin{array}{c}\text { Crack Area } \\
\text { in Image }\end{array}$ & $\begin{array}{c}\text { Actual } \\
\text { Crack Area }\end{array}$ & $\begin{array}{c}\text { Crack } \\
\text { Density }\end{array}$ \\
\hline Sample 5 & $500 \mu \mathrm{m}$ & $0.2318 \mathrm{~mm}^{2}$ & $115.9 \mu \mathrm{m}^{2}$ & $3.02 \%$ \\
\hline Sample 6 & $500 \mu \mathrm{m}$ & $0.1001 \mathrm{~mm}^{2}$ & $50.05 \mu \mathrm{m}^{2}$ & $1.30 \%$ \\
\hline
\end{tabular}




\section{CONCLUSION}

This paper described the spatial resampling process on the concrete SEM specimens. The down-sampling image procedure has eliminated unnecessary image label and hence, generated a geo-referenced image. Testing different approaches of image filtering, obviously the adaptive box filter is generally better in enhancing noisy SEM images. In the classification and segmentation of large indefinite pixels, the applied K-means clustering improved the image samples through the generation of 15 possible cluster groups. It shows the distribution of k-cluster has been affected by the selection of k-centroids and influenced by the differential contrast of the dissimilar cementitious paste in concrete specimens. The clustered mapping of classified microstructure properties map shows that high percentage cluster was identified to be correlated to the major elements distribution such as Oxide $(\mathrm{O})$, Silicon $(\mathrm{Si})$ and Carbon (C). In addition, the crack density for resampled SEM images had been acknowledged and measured accordingly by exaggerating the magnification factor during SEM image acquisition. In short, with the application of modern imaging techniques such as Scanning Electron Microscopy (SEM), with a georeferenced image, much conceivable research can be conducted to specifically describe the concrete microstructure properties.

\section{REFERENCES}

1. Weerheijm, J Editor(s) 2013. Introduction to concrete: a resilient material system, In Woodhead Publishing Series in Civil and Structural Engineering, Understanding the Tensile Properties of Concrete, Woodhead Publishing, 115.

2. Scrivener, K, Snellings, R and Lothenbach, B 2016. A Practical Guide to Microstructural Analysis of Cementitious Materials, CRC Press, $1^{\text {st }}$ Edition, $540 \mathrm{pp}$.

3. Giannuzzi, L 2018. Scanning Electron Microscopy and X-Ray Microanalysis, $4^{\text {th }}$ Edition, Springer, $550 \mathrm{pp}$.

4. Leite, $\mathrm{M}$ and Monteiro, $\mathrm{P}$ 2016. Microstructural analysis of recycled concrete using x-ray microtomography. Cement and Concrete Research 81, $38-48$.

5. Kong, Y, Wang, $\mathrm{P}, \mathrm{Liu}, \mathrm{S}, \mathrm{Zhao}, \mathrm{G}$ and Peng, $\mathrm{Y}$ 2016. SEM analysis of the interfacial transition zone between cement-glass powder paste and aggregate of mortar under microwave curing. Materials 9(9), 733.

6. Narasimha, R and Ahmed N 2019. Experimental study on TGA, XRD and SEM Analysis of Concrete with Ultrafine Slag. International Journal of Engineering, IJE Transactions B: Applications 32(5), 679-684. 
7. Mehran, Y and Katayoon S 2014. Automated segmentation of concrete images into microstructures: A comparative study. Computers and Concrete 14(3), 315-325.

8. Lucas, D, Mauro, D, Samuel, M, Sébastien L and Jocelyn, C 2015. SemiAutomatic Classification of Cementitious Materials using Scanning Electron Microscope Images. Journal of Electronic Imaging 24(6), 061109.

9. Zhu, X, Yuan, Y, Li, L, Du, Y and Li, F 2017. Identification of interfacial transition zone in asphalt concrete based on nano-scale metrology techniques. Materials \& Design 129, 91-102.

10. Zhang, L, Zhang, Y, Liu, C, Liu, L and Tang, K 2017. Study on microstructure and bond strength of interfacial transition zone between cement paste and high-performance lightweight aggregates prepared from ferrochromium slag. Construction and Building Materials 142, 31-41.

11. Vargas, P, Restrepo-Baena, O and Tobón, J.I 2017. Microstructural analysis of interfacial transition zone (ITZ) and its impact on the compressive strength of lightweight concretes. Construction and Building Materials 137, 381-389.

12. Arun, $\mathrm{M}$ and Sumathi, $\mathrm{P}$ 2018. Crack detection using image processing: A critical review and analysis, Alexandria Engineering Journal 57(2), 787798.

13. Alam, S.Y, Loukili, A.F and Grondin, E.R 2015. Use of the digital image correlation and acoustic emission technique to study the effect of structural size on cracking of reinforced concrete. Engineering Fracture Mechanics 143, 17-31.

14. Romulo, G.L and Sidney, N. G 2016. Automatic crack detection and measurement based on image analysis. IEEE Transactions on Instrumentation and Measurement 65(3), 583-590.

15. Wang, D, Shi, C, Wu, Z, Xiao, J, Huang, Z and Fang, Z 2015. A Review on Ultra High-Performance Concrete: Part II. Hydration, Microstructure and Properties, Journal of Construction and Building Materials 96, 368-377.

16. Li, J.J, Niu, J.G, Wan, C.J, Jin, B and Yin, Y. L 2016. Investigation on Mechanical Properties and Microstructure of High-Performance Polypropylene Fiber Reinforced Lightweight Aggregate Concrete, Journal of Construction and Building Materials 118, 27-35.

17. Shen, W, Liu, Y, Cao, L, Huo, X, Yang, Z, Zhou, C, He, P and Lu, Z 2017. Mixing Design and Microstructure of Ultra High Strength Concrete with Manufactured Sand, Journal of Construction and Building Materials 143, 312-321.

18. Rakhi, C, Parneet, K.R and Navneet, S.R 2011. Spatial Domain based Image Enhancement Techniques for Scanned Electron Microscope (SEM) images. IJCSI International Journal of Computer Science 8(4/2), 580-586. 
19. Buckman, J, Bankole, S.A, Zihms, S, Lewis, H, Couples, G and Corbett, P. W 2017. Quantifying Porosity through Automated Image Collection and Batch Image Processing: Case Study of Three Carbonates and an Aragonite Cemented Sandstone. Geosciences 7(3), 70.

20. Yu, C, Sun, W and Karen, S. J 2014. Application of image analysis based on SEM and chemical mapping on PC mortars under sulfate attack. Journal of Wuhan University of Technology-Mater. Sci. Ed. 29(3), 534-539.

21. Paul, E.S, Jeffrey, W. B, and Pan Feng 2015. Quantitative Imaging of Clinker and Cement Microstructure. National Institute of Standards and Technology Technical Note 1877, 46 pp.

22. Meulenyzer, S.P, Chanussot, J, Crombez, S and Chen J.J 2013. Spectralspatial image processing strategies for classifying multi-spectral SEM-EDS $X-R A Y$ maps of supplementary cementitious materials. $14^{\text {th }}$ Euroseminar on Microscopy Applied to Building Materials, (EMABM). Helsingor, Denmark.

23. Bhabatosh, C and Dutta, D 2011. Digital Image Processing and Analysis, Prentice-Hall, India. $2^{\text {nd }}$ edition. 365 pp.

24. $\mathrm{Wu}, \mathrm{Q}$, Merchant, $\mathrm{F}$ and Castleman, K. (eds). Microscope Image Processing, Elsevier Academic Press. 2010.

25. Annadurai, S 2007. Fundamentals of Digital Image Processing, Pearson, India,440 pp.

26. Krig S 2014. Image Pre-Processing. Computer Vision Metrics. A press, Berkeley, CA.,39-83.

27. Wong, H.S, Head, M.K and Buenfeld, N.R 2006. Pore segmentation of cement-based materials from backscattered electron images. Cement \& Concrete Research 36(6), 1083-1090

28. Ezoji, M and Iravani, S 2016. A General Framework for 1-D Histogrambased Image Contrast Enhancement, IJE Transactions A: Basics 29(10), 1384-1391.

29. Tuzlukov, V. Signal Processing Noise, CRC Press, United States. 2002. 688 pp.

30. Timischl, F, Date, M and Nemoto, S 2012. A Statistical Model of Signalnoise in Scanning Electron Microscopy. Scanning 34(3), 137-144.

31. Marturi, N, Dembélé, S and Piat, N 2014. Scanning Electron Microscope Image Signal-to-Noise Ratio Monitoring for Micro-Nanomanipulation. Scanning 36(4), 419-429.

32. Rajvardhan, O 2016. A Study of Digital Image Segmentation Techniques. International Journal of Engineering and Computer Science 5(12), 1977919783.

33. Li, Y, Guo, W and Li, H 2016. Quantitative Analysis on Ground Blast Furnace Slag Behavior in Hardened Cement Pastes Based on Backscattered 
Electron Imaging and Image Analysis Technology, Construction and Building Materials 110(1), 48-53.

34. Vidal, M, Ostra, M, Imaz, N, García-Lecina, E and Ubide, C 2016. Analysis of SEM Digital Images to Quantify Crack Network Pattern Area in Chromium Electrodeposits, Surface and Coatings Technology 285(1), 289297.

35. Drumetz, L, Dalla Mura, M, Meulenyzer, S, Lombard, S and Chanussot, J 2015. Semi-Automatic Classification of Cementitious Materials Using Scanning Electron Microscope Images, Journal of Electronic Imaging 24(6), $1-53$.

36. Gopan, V and Wins, K 2016. Quantitative Analysis of Grinding Wheel Loading Using Image Processing. Procedia Technology 25(1), 885-891.

37. Campbell, A, Murray, P, Yakushina, E, Marshall, S and Ion, W 2018. New Methods for Automatic Quantification of Microstructural Features Using Digital Image Processing. Materials \& Design. 141(1), 395-406.

38. Meulenyzer, S, Chanussot, J, Chen, J and Crombez, S. Spectral-Spatial Image Processing Strategies for Classifying Multispectral SEM-EDS X-Ray Maps of Cementitious Materials. Proceedings of $14^{\text {th }}$ Euroseminar on Microscopy Applied to Building Materials (EMABM), Helsingor, Denmark, 2013, 1-4.

39. Angelin, A, Da Silva, F, Barbosa, L, Lintz, R, De Carvalho, M and Franco, $\mathrm{R}$ 2017. Voids Identification in Rubberized Mortar Digital Images Using KMeans and Watershed Algorithms. Journal of Cleaner Production 164(4), 455-464.

40. Soroushian, P, Elzafraney, M and Nossoni, A 2003. Specimen Preparation and Image Processing and Analysis Techniques for Automated Quantification of Concrete Microcracks and Voids, Cement and Concrete Research 33(12), 1949-1962.

41. Eliason, E and Mcewen, A 1990. Adaptive Box Filters for Removal of Random Noise from Digital Images. Photogrammetric Engineering and Remote Sensing 56(4),453-458.

42. Wu, J 2012. Advances in K-means Clustering, Springer Theses, SpringerVerlag Berlin Heidelberg. 178 pp.

Editor received the manuscript: 21.10 .2019 